\title{
Change of Bike-share Usage in Five Cities of United States during COVID-19
}

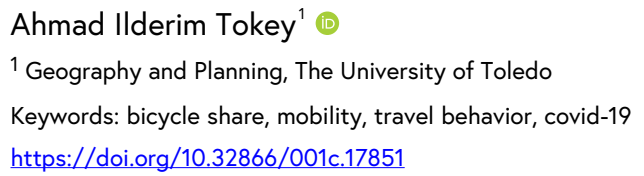

Findings

\begin{abstract}
This study explores how bike-share usage varied over the six months of the coronavirus pandemic (March'20-August'20) in five US cities. First, it finds that in most of the months, the changes (both increase or decrease) of bike-share usage from the preceding months are significantly higher in central tracts than peripheral tracts. This finding has more statistical significance for cities that are popular for biking (e.g. DC, Boston, Portland). Second, biking is found to be positively associated with cities' non-work trip rate and people's COVID exposure and it was diminished with more people maintaining social distance and staying at home.
\end{abstract}

\section{RESEARCH QUESTIONS AND HYPOTHESES}

As an effect of COVID-19, the ridership of bike-share services plummeted with the economic shutdown wave. Teixeira and Lopez (2020) found that bike-sharing in New York, comparative to transit, show higher resiliency and a lower drop in ridership. Analyzing ridership of bike-share in Washington DC, Boston, Pittsburgh, Columbus, and Portland, this exploratory study tries to answer two questions:

1. How has the usage of bike-share services in areas with different distances from $\mathrm{CBD}$ varied during the pandemic?

2. Is the weekly bike-share ridership of a city correlated with its overall trip rate, social distancing measures, and COVID cases?

\section{METHODS AND DATA}

This study analyzed five large cities of the USA (with at least 65,000 workers) that differ in modal dominancy. While Washington, DC and Boston have high transit mode share (34.8\% and $31.4 \%$ respectively), Pittsburgh and Columbus are mostly car dominant cities with car share of $70.6 \%$ and $80.3 \%$. Portland is bike-friendly and has moderate transit and car share $(11 \%$ and $61.1 \%$, respectively). Although several other cities potentially met the criteria, the most updated bike-share data's unavailability inhibited their inclusion in this study. The critical dataset here is the system data of bike-share services (Capital Bikeshare 2020; Bluebikes 2020; Healthy Ride 2020; CoGo Bike-share 2020; Biketown 2020) with temporal and spatial information of origins and destinations of bike-share trips. For cleaning the data, trips less than 3 minutes long or longer than 3 hours were removed. 
First, the bike-share activity of census tracts between February 2020 to August 2020 was calculated with the following formula:

$$
\text { activity }=T_{g}+T_{d}-T_{i}
$$

Here, $T_{g}, T_{d}, T_{i}$ are the number of generated, terminated, and intra-tract trips of a tract, respectively (Bai and Jiao 2020). The dependent variable (DV) is the month-to-month change (\%) of bike-share activity and calculated with the following simple formula:

$$
\text { activity }_{m}=\frac{\text { activity }_{m}-\text { activity }_{m-1}}{\text { activity }_{m}} \times 100
$$

Here, $m$ is month, ranged from March '20 to August' 20. Each tract has a variable (distCBD) with the distance of its nearest CBD. Assessing the spatial extent of bike-share usage, Boston and DC were found to be polycentric while Columbus, Portland, and Pittsburgh were considered monocentric cities. To formalize the association of the month-to-month variation of activity within a tract and its distance from CBD, six General Linear Models (GLM) with random intercepts and random slopes were fitted for the six months. The form of the models is:

$$
Y_{i j}=\beta_{o}+\beta_{j} * \text { City }+\beta_{i j 1} * \operatorname{distCBD}+\beta_{i j 2} * \text { City } * \operatorname{distCBD}+\beta_{i j 3} * \text { control }+\varepsilon_{i j}
$$

Here, $Y_{i j}$ is DV for the tract $\mathrm{i}$ of city $\mathrm{j},\left(\beta_{o}+\beta_{j}\right)$ is the random intercept for the city $\mathrm{j}$, and $\left(\beta_{i j 1}+\beta_{i j 2}\right)$ are the random slopes for distCBD in tract $\mathrm{i}$ of city $\mathrm{j}$.

Setting 2019 as a baseline would be a common approach for comparison. However, as the shift of usage from 2019 cannot be solely attributable to Coronavirus for some substantial policy changes in 2020 (i.e. setting first stations and dockless hubs in 263 tracts, launching electric and dockless bikes in three cities), preceding months of 2020, free from policy change effect, served as a baseline offering the ability to capture every turn during the Coronavirus.

Secondly, each study area's total weekly trips for 26 weeks (March'20-August'20) were calculated. Then an assessment was carried out to find its correlation with seven mobility, social distancing, and COVID related metrics that include work and non-work trips/person (all mode), social distancing index (SDI) (in 0-100 scale where 100 denotes the highest degree of maintaining social distance), \% working from home, \% staying home, COVID exposure/1000 people and new cases/1000 people (Maryland Transportation Institute 2020). These metrics have daily records for every county in the USA. Here, the weekly average is taken for the counties that intersect the study areas. 


\section{FINDINGS}

Before looking at the month-to-month changes, it is useful to see the entire bike-share trips over time and compare them with total trips in 2019 from Figure 1. This figure tells us that every city had a drop in bike-share usage during the first wave of COVID-19 in March-April and a subsequent jump in May as cities started to reopen gradually. Bernardes (2020) also found a similar trend for New York. In contrast, other surveys in Australia (Beck and Hensher 2020) and India (Meena 2020) did not suggest a substantial increase in bicycling after lockdowns. In our case, while as of August, cities with popular bike-share services (Boston, DC, and Portland) are struggling to regain the same ridership as 2019, car dominant cities (Columbus, Pittsburgh) had crossed it in May, suggesting an overwhelming modal shift. To this end, Table $\underline{1}$ represents the summary of month-to-month changes in bike-share usage in these cities. The intercept ( $\beta 0)$ and city-specific fixed effect $(\beta j)$ tell the monthly changes in a city which is consistent with the figure 1 . In April, bike-usage had decreased in all cities equivocally and DC, Boston and Columbus had significant decreases. In the next month, an increase in ridership was evident in all cities showing significance in DC, Pittsburgh and Columbus. In June and July, with the rise of country's second wave of Coronavirus, the growth of bike-demand dropped significantly in most of the cities (except for Columbus in June and DC in July) and was even halted in Pittsburgh and Columbus. User's response towards bikeshare during the fall of the second wave (mid-July to August) was mixed. While in August, Boston and Portland were persistently experiencing the slow growth (20\% and 3.7\% respectively), DC had $81 \%$ more trips than July.

It is well-documented that the usage of bike-share diminishes with distance from CBD (Faghih-Imani et al. 2014; Wang et al. 2016; Noland, Smart, and Guo 2016; Yang et al. 2020) and an exploratory regression on the study areas (not reported here) also confirms this relation for COVID-19 era. Instead of cross-sectional usage, this study's particular interest is to see the fluctuations of usage in tracts with different distances from CBD. There are two things from Table 1 that should be elucidated. Firstly, a random slope $\left(\beta_{i j 1}+\beta_{i j 2}\right)$ coupled with an opposite-signed city-specific fixed effect $\left(\beta_{o}+\beta_{j}\right)$ in Table 1 tells us that in a particular city, the within-tract increase/decrease of ridership is higher for a tract closer to CBD. Secondly, a significant interaction effect with an insignificant main effect tells us that the DV and city-specific dummies' relation entirely depends on the distCBD. Considering the sign and significance, this study, with few exceptions, explores a consistent pattern in cities popular for biking (DC, Boston, Portland). That is, when biking fell-off, it decreased more remarkably in the areas closer to the $\mathrm{CBD}$. Reversely, when a city was revitalized with cycling, the reinforcement was quicker again in central tracts than the peripheral parts. Chai et al. (2020) found a similar finding in Beijing. The car-oriented cities (Columbus and Pittsburgh), however, lacks the statistical power to reach this consensus in most of the months. 

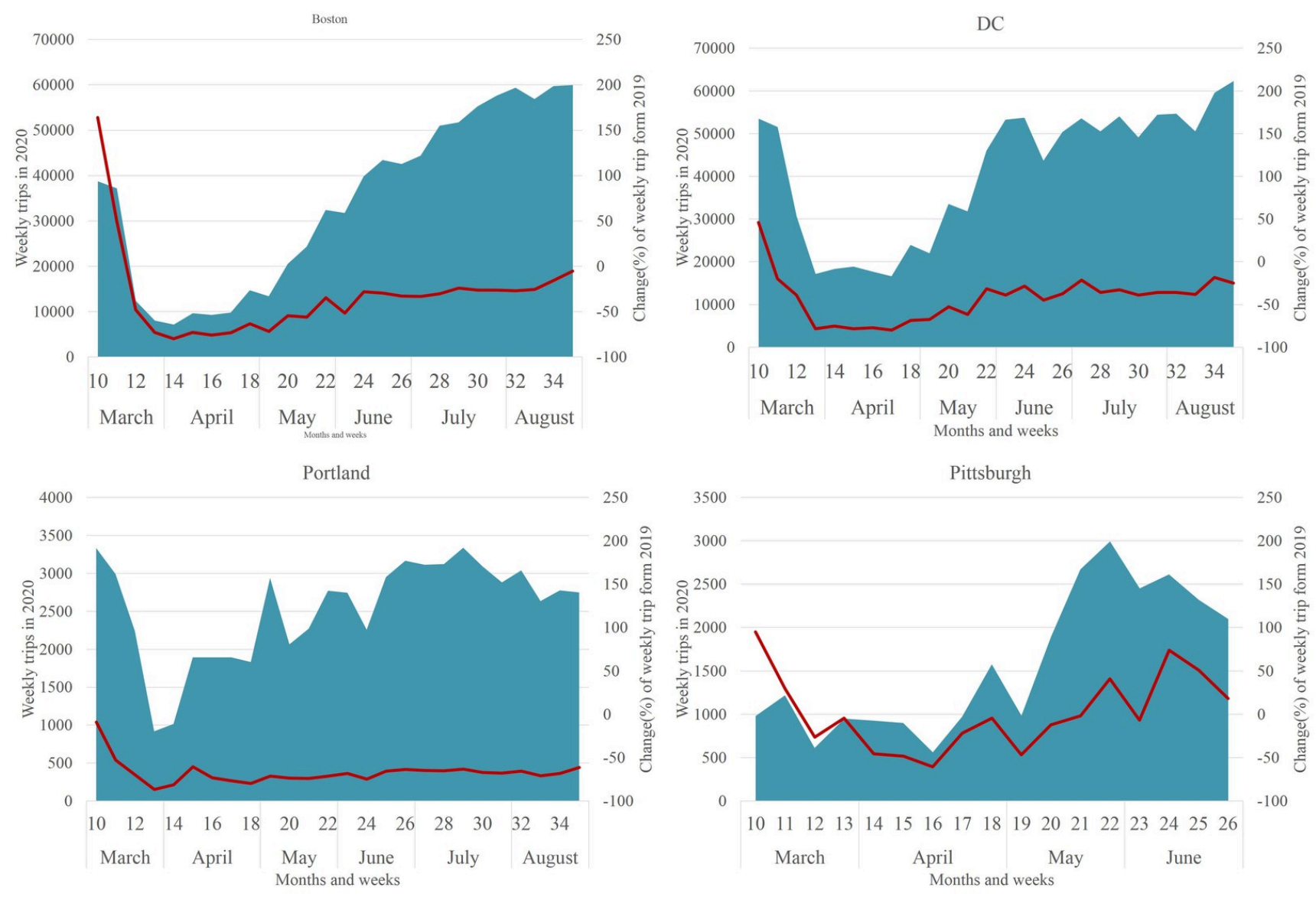

Columbus

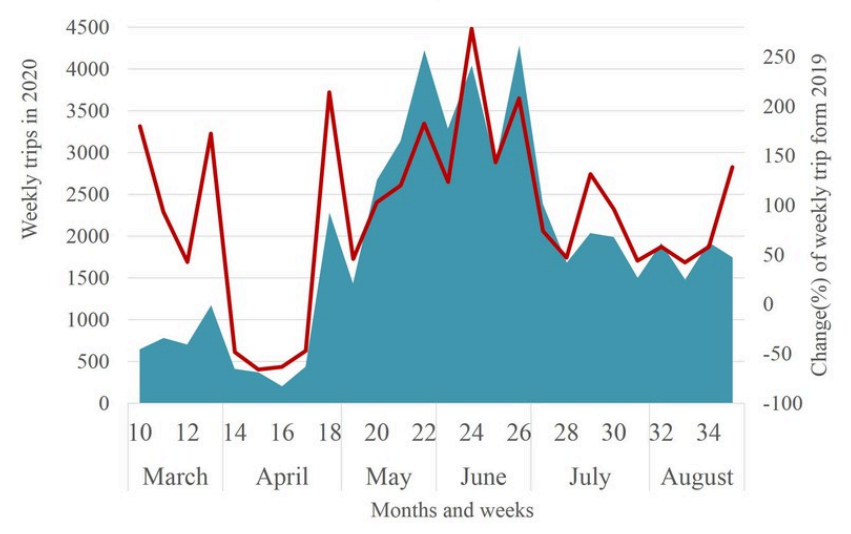

- total trip in 2020 (left axis)

-change(\%) of total trip from 2019 (right axis)

Figure 1. Total weekly trips in 2020 and changes with 2019

While there is a growing body of literature suggesting that reduced mobility helps block COVID-19 (Jiang and Luo 2020; Badr et al. 2020; Chinazzi et al. 2020; Cartenì, Di Francesco, and Martino 2020), the effect of bike-mobility is not widely explored. Table 2 represents Pearson's correlation coefficients of weekly bike-share trips and the seven metrics mentioned in the method section. Weekly bike-share trips, revealing no relation with work trip rates, show highly positive associations with a city's non-work trip rates (except Columbus). This finding suggests the overwhelming use of bike-share for non-commuting trips. It is also intuitive that biking dropped significantly (except Columbus) when more people stayed at home and maintained social distance. Surprisingly, 
Table 1. Result of mixed effect model

\begin{tabular}{|c|c|c|c|c|c|c|}
\hline \multirow[t]{2}{*}{ variables } & \multicolumn{6}{|c|}{$\begin{array}{l}\text { Dependent variable: change (\%) of bike-share activity of a month from the previous month } \\
\text { Correlation coefficient (marginal effects in parenthesis) }\end{array}$} \\
\hline & march & April & may & June & July & august \\
\hline Intercept $\left(\beta_{0}\right)$ & 12.072 & $-30.96^{* * *}$ & $91.01^{* * *}$ & $45.287^{* * *}$ & -14.424 & $81.119^{* * *}$ \\
\hline $\begin{array}{l}\text { bus stop density } \\
\text { (control) }\end{array}$ & -0.11 & $-0.132^{*}$ & -0.008 & $0.124^{*}$ & $-0.161^{*}$ & -0.083 \\
\hline $\operatorname{distCBD}\left(\beta_{i j 1}\right)$ & 1.033 & 0.621 & 1.261 & $-1.078^{*}$ & $7.158^{* * *}$ & -0.737 \\
\hline \multicolumn{7}{|l|}{ Fixed-effect $\left(\beta_{j}\right)$} \\
\hline $\mathrm{DC}$ & base & & & & & \\
\hline Boston & $\begin{array}{l}-33.645^{*} \\
(-21.57)\end{array}$ & $\begin{array}{l}-22.234^{* *} \\
(-53.19)\end{array}$ & $\begin{array}{l}28.711 \\
(119.72)\end{array}$ & $\begin{array}{l}18.55^{* *} \\
(63.83)\end{array}$ & $\begin{array}{l}68.645^{* * *} \\
(54.22)\end{array}$ & $\begin{array}{l}-60.933^{* *} \\
(20.18)\end{array}$ \\
\hline Portland & $\begin{array}{l}-30.808 \\
(-18.73)\end{array}$ & $\begin{array}{l}-0.761 \\
(-31.72)\end{array}$ & $7.48(98.49)$ & $\begin{array}{l}-24.882^{* *} \\
(20.4)\end{array}$ & $\begin{array}{l}49.249^{* *} \\
(34.82)\end{array}$ & $\begin{array}{l}-77.38^{* *} \\
(3.73)\end{array}$ \\
\hline Pittsburgh & $\begin{array}{l}19.938 \\
(32.01)\end{array}$ & $\begin{array}{l}14.091 \\
(-16.87)\end{array}$ & $\begin{array}{l}138.762^{* *} \\
(229.77)\end{array}$ & $\begin{array}{l}-49.545^{* *} \\
(-4.25)\end{array}$ & & \\
\hline Columbus & $\begin{array}{l}359.36^{* * *} \\
(371.43)\end{array}$ & $\begin{array}{l}-29.53^{*} \\
(-60.49)\end{array}$ & $\begin{array}{l}615.166^{* * *} \\
(706.17)\end{array}$ & $\begin{array}{l}-9.358 \\
(35.92)\end{array}$ & $\begin{array}{l}-45.232^{*} \\
(-59.65)\end{array}$ & $\begin{array}{l}24.259 \\
(105.37)\end{array}$ \\
\hline \multicolumn{7}{|l|}{$\begin{array}{l}\text { Interaction terms } \\
\left(\beta_{i j 2}\right)\end{array}$} \\
\hline $\mathrm{DC} \times \operatorname{distCBD}$ & base & & & & & \\
\hline Boston $\times$ distCBD & $\begin{array}{l}\text { 10.337** } \\
(11.37)\end{array}$ & $\begin{array}{l}10.077^{* * *} \\
(10.69)\end{array}$ & $\begin{array}{l}47.379^{* * *} \\
(48.64)\end{array}$ & $\begin{array}{l}-2.882 \\
(-3.96)\end{array}$ & $\begin{array}{l}-12.938^{* * *} \\
(-5.78)\end{array}$ & $\begin{array}{l}0.813 \\
(0.07)\end{array}$ \\
\hline Colombus $\times$ distCB & $\begin{array}{l}31.98^{* * *} \\
(33.01) \\
\end{array}$ & $4.581(5.2)$ & $\begin{array}{l}-4.333 \\
(-3.07) \\
\end{array}$ & $4.481(3.4)$ & $\begin{array}{l}-2.119 \\
(5.03)\end{array}$ & $\begin{array}{l}-14.098^{* *} \\
(-14.83)\end{array}$ \\
\hline Portland $\times$ distCBD & $-0.126(0.9)$ & $\begin{array}{l}6.302^{* *} \\
(6.92)\end{array}$ & $-9.58^{*}(-8.31)$ & $\begin{array}{l}-5.855^{* * *} \\
(-6.93)\end{array}$ & $-4.39(2.76)$ & $\begin{array}{l}-2.938 \\
(-3.67)\end{array}$ \\
\hline Pittsburgh $\times$ distCB & $2.944(3.97)$ & $\begin{array}{l}6.028 \\
(6.65) \\
\end{array}$ & $\begin{array}{l}-22.083^{*} \\
(-20.82) \\
\end{array}$ & $\begin{array}{l}8.323^{* *} \\
(7.24) \\
\end{array}$ & & \\
\hline $\mathrm{F}$ & $74.82^{* * *}$ & $7.33^{* * *}$ & $54.77^{* * *}$ & $20.06^{* * *}$ & $21.27^{* * *}$ & $5.965^{* * *}$ \\
\hline df & 547 & 566 & 589 & 608 & 598 & 705 \\
\hline Adjusted $\mathrm{R}^{2}$ & 0.57 & 0.10 & 0.48 & 0.24 & 0.21 & .053 \\
\hline
\end{tabular}

${ }^{* * *} \mathrm{p}<.001{ }^{* *} \mathrm{p}<.05{ }^{*} \mathrm{p}<.10$

working from home did not show any significant correlation with usage. A higher rate of cycling generally came up with an increase in COVID exposure. While Boston and DC had a significant drop in cycling with the increase of daily new cases, a counterintuitive finding was significant in Portland for biking at the weekend. The distinctive biking pattern in Columbus revealed in every part of this study expresses the need to conduct a separate exclusive study on it. 
Table 2. Correlations with weekly bike-share usage.

\begin{tabular}{|c|c|c|c|c|c|c|c|c|c|c|}
\hline \multirow[b]{2}{*}{ Metrics (weekly average) } & \multicolumn{5}{|c|}{ Total trip in weekday } & \multicolumn{5}{|c|}{ Total trip in weekend } \\
\hline & Boston & DC & Portland & Pittsburgh & Columbus & Boston & DC & Portland & Pittsburgh & Columbus \\
\hline Work trips/person & 0.17 & 0.27 & 0.33 & -0.18 & -0.28 & - & - & - & - & - \\
\hline Non-work trips/person & $.95^{* *}$ & $.92^{* *}$ & $.80^{* *}$ & $.83^{* *}$ & 0.51 & $.87^{* *}$ & $.79^{* *}$ & $.57^{* *}$ & $.64^{* *}$ & 0.54 \\
\hline Social distancing index & $-89^{* *}$ & $-.87^{* *}$ & $-.86^{* *}$ & $-.67^{* *}$ & -0.30 & $-.70^{* *}$ & $-.61^{* *}$ & $-.48^{*}$ & $-.50^{*}$ & -0.37 \\
\hline \% staying home & $-86^{* *}$ & $-.86^{* *}$ & $-85^{* *}$ & $-.66^{* *}$ & -0.35 & $-.67^{* *}$ & $-.60^{* *}$ & $-.46^{*}$ & -0.46 & -0.39 \\
\hline$\%$ working from home & -0.21 & -0.15 & -0.26 & -0.16 & -0.13 & 0.15 & 0.33 & 0.23 & 0.22 & 0.02 \\
\hline COVID exposure/1000 people & $.65^{* *}$ & $.58^{* *}$ & 0.34 & $.75^{* *}$ & $.58^{*}$ & $.82^{* *}$ & $.69^{* *}$ & $.48^{*}$ & $.82^{* *}$ & $.75^{* *}$ \\
\hline New cases/1000 people & $-.72^{* *}$ & $-.47^{*}$ & 0.36 & -0.13 & 0.41 & $-.53^{* *}$ & -0.02 & $.61^{* *}$ & -0.01 & 0.50 \\
\hline New cases/1000 people in previous week & $-.63^{* *}$ & -0.28 & 0.35 & -0.15 & 0.42 & $-.41^{*}$ & 0.24 & $.59^{* *}$ & 0.08 & 0.49 \\
\hline
\end{tabular}

${ }^{* *} \mathrm{p}<.001{ }^{*} \mathrm{p}<.05$ 
Some limitations of this study should be noted. Firstly, understanding six models might be cumbersome for readers and a single model handling temporal and spatial heterogeneity would be more graspable. Secondly, aggregating the bikeshare usage by weeks offered us small and statistically weak sample size $(n=26)$ for Pearson correlation test. Despite all, this research's simplistic design allows readers to gain a comprehensive and general understanding of the issues discussed. Deploying advanced modeling techniques, future studies can look into local factors including land use, closure and reopening of different services, and transit agency policies.

\section{ACKNOWLEDGMENTS}

I want to thank the two anonymous reviewers for their constructive comments that substantially helped to shape the manuscript. I am also grateful to Shefa Arabia, Brittany Jones, Rebekka Apardian, and Olivia Zolciak for their helpful suggestions. 


\section{REFERENCES}

Badr, Hamada S, Hongru Du, Maximilian Marshall, Ensheng Dong, Marietta M Squire, and Lauren M Gardner. 2020. "Association between Mobility Patterns and COVID-19 Transmission in the USA: A Mathematical Modelling Study.” The Lancet Infectious Diseases 20 (11): 1247-54. https://doi.org/10.1016/s1473-3099(20)30553-3.

Bai, Shunhua, and Junfeng Jiao. 2020. "Dockless E-Scooter Usage Patterns and Urban Built Environments: A Comparison Study of Austin, TX, and Minneapolis, MN." Travel Behaviour and Society 20 (July): 264-72. https://doi.org/10.1016/j.tbs.2020.04.005.

Beck, Matthew J., and David A. Hensher. 2020. "Insights into the Impact of COVID-19 on Household Travel and Activities in Australia - The Early Days under Restrictions." Transport Policy 96 (September): 76-93. https://doi.org/10.1016/j.tranpol.2020.07.001.

Biketown. 2020. “System Data.” https://www.biketownpdx.com/system-data.

Bluebikes. 2020. “System Data.” https://www.bluebikes.com/system-data.

Capital Bike-share. 2020. "System Data.” https://www.capitalbike-share.com/system-data.

Cartenì, Armando, Luigi Di Francesco, and Maria Martino. 2020. "How Mobility Habits Influenced the Spread of the COVID-19 Pandemic: Results from the Italian Case Study." Science of the Total Environment 741 (November): 140489. https://doi.org/10.1016/j.scitotenv.2020.140489.

Chai, X., X. Guo, J. Xiao, and J. Jiang. 2020. "Spatiotemporal Analysis of Share Bike Usage during the COVID-19 Pandemic: A Case Study of Beijing." ArXiv Preprint.

Chinazzi, M., J.T. Davis, M. Ajelli, C. Gioannini, M. Litvinova, S. Merler, and C. Viboud. 2020. "The Effect of Travel Restrictions on the Spread of the 2019 Novel Coronavirus (COVID-19) Outbreak.” Science 368 (6489): 395-400.

CoGo Bike-share. 2020. “System Data.” https://www.cogobike-share.com/system-data.

Faghih-Imani, A., N. Eluru, A. M. El-Geneidy, M. Rabbat, and U. Haq. 2014. "How Land-Use and Urban Form Impact Bicycle Flows: Evidence from the Bicycle-Sharing System (BIXI) in Montreal." Journal of Transport Geography 41: 306-14. https://doi.org/10.1016/ j.apgeog.2019.102130.

Healthy Ride. 2020. "Data.” https://healthyridepgh.com/data/.

Jiang, J., and L. Luo. 2020. "Influence of Population Mobility on the Novel Coronavirus Disease (COVID-19) Epidemic: Based on Panel Data from Hubei, China." Global Health Research and Policy 5: 1-10.

Maryland Transportation Institute. 2020. "University of Maryland COVID-19 Impact Analysis Platform.” University of Maryland, College Park, USA. https://data.covid.umd.edu.

Meena, S. 2020. "Impact of Novel Coronavirus (COVID-19) Pandemic on Travel Pattern: A Case Study of India." Indian Journal of Science and Technology 13 (24): 2491-2501. https://doi.org/ $\underline{10.17485 / \mathrm{IJST} / \mathrm{v} 13 \mathrm{i} 24.958 .}$.

Noland, Robert B., Michael J. Smart, and Ziye Guo. 2016. "Bikeshare Trip Generation in New York City." Transportation Research Part A: Policy and Practice 94 (December): 164-81. https://doi.org/10.1016/j.tra.2016.08.030. 
Teixeira, João Filipe, and Miguel Lopes. 2020. "The Link between Bike Sharing and Subway Use during the COVID-19 Pandemic: The Case-Study of New York's Citi Bike.” Transportation Research Interdisciplinary Perspectives 6 (July): 100166. https://doi.org/10.1016/ j.trip.2020.100166.

Wang, Xize, Greg Lindsey, Jessica E. Schoner, and Andrew Harrison. 2016. "Modeling Bike Share Station Activity: Effects of Nearby Businesses and Jobs on Trips to and from Stations." Journal of Urban Planning and Development 142 (1): 04015001. https://doi.org/ $\underline{10.1061 /(a s c e) \text { up. 1943-5444.0000273. }}$

Yang, Hongtai, Yibei Zhang, Lizhi Zhong, Xiaojia Zhang, and Ziwen Ling. 2020. "Exploring Spatial Variation of Bike Sharing Trip Production and Attraction: A Study Based on Chicago's Divvy System.” Applied Geography 115 (February): 102130. https://doi.org/10.1016/ j.apgeog.2019.102130. 